\title{
TECNOLOGIAS DA INFORMAÇÃO E NOVOS ATORES SOCIAIS
}

\section{Modernas tecnologias têm possibilitado o surgimento de novos atores sociais, os quais podem utilizar de forma criativa as estratégias comunicacionais que fortaleçam a sociedade civil}

Os assuntos econômicos mundiais assim como as questões políticas, culturais e mesmo educacionais são tratados, hoje, em todas as partes do mundo, mais do que nunca, sob o olhar vigilante de bancos e corporações multinacionais, através dos conglomerados da mídia cultural, em estreita cooperação com os Estados nacionais.Exemplo mais recente foi o rígido esquema de vigilância sobre as relações internacionais, mantido por Washington através de um formidável aparato de difusão de informações. $\mathrm{O}$ exercício do poder exigiu - justamente no país da liberdade - um controle sem precedentes do aparato doméstico de divulgação da informação, principalmente das redes de televisão, visando impedir que os habitantes do país tivessem consciência daquilo que boa parte do resto do mundo pensava sobre as bombas "inteligentes" e o massacre ocorrido na guerra contra o Iraque $^{1}$. E o que é mais sintomático: poucas vozes se insurgiram, nos Estados Unidos, contra o projeto de controle político da informação.

Essa omissão se justifica: a comunicação e seus intrincados caminhos de reconstrução do mundo através da produção da notícia têm sido, através da História, parte inseparável e fundamental de qualquer ordem econômica, política e cultural. E, para tanto, a confiança dos usuários nos sistemas de in- formação não pode ser abalada, mesmo que em função disso seja necessário mobilizar, através do marketing mundial, somas incalculáveis de dinheiro.

\section{AS ALIANÇAS QUE SUSTENTAM O MODELO DE COMUNICAÇÃO}

O Ocidente fundou seu sistema de acumulação de riquezas no controle dos processos de comunicação. Um controle que surge como resultado de um equilíbrio constante entre três processos em si muito dinâmicos:

a) a implantação de infra-estruturas de natureza técnica (redes de telefonia, construção ou aluguel de satélites, fabricação de aparelhos de reprodução de imagens e sons etc.);

b) a criação de sólidas alianças entre o Estado e o empresariado, com o Governo distribuindo graciosamente as concessões para o uso dos canais de radiodifusão, e

\section{O AUTOR}

Ismar de Oliveira Soares

Professor Associado do Departamento de Comunicações e Artes da ECA-USP e Presidente da UCLAP - Uniāo Católica Latino-Americana de Imprensa.

1. SHILLER, Herbert L. As multinacionais da mídia e a transição democrática na América Latina. Comunicação \& Política. CBELA, São Paulo, XI, 16, 1992, p.93-103. 
os empresários subsidiando, por sua vez, com seus anúncios, a produção e a veiculação dos produtos culturais;

c) a busca, por parte dos meios de comunicação, de legitimidade social, através da mobilização em torno da defesa dos supostos interesses dos receptores; os meios de comunicação afirmam-se como portavozes da sociedade ${ }^{2}$.

A legitimidade da aliança Estado/empresariado tem sido obtida através da criação de mecanismos que resultam em consensos favoráveis à manutenção do sistema comunicacional tal como está, excluindo os demais setores da sociedade.

Um dos mecanismos utilizados para a criação de tal consenso tem sido a transformação da Comunicação Social em objeto de admiração, distante, inacessível, um verdadeiro fetiche.Reafirma-se, deste modo, a visão funcionalista segundo a qual "ao consumidor cabe apenas consumir" e "aos produtores, produzir", descaracterizando-se, pela base conceitual, o papel dos grupos sociais enquanto produtores de cultura e, portanto, de comunicadores.

Outro mecanismo é a permanência ainda que mascarada ou camuflada - do controle político sobre os processos de produção das mensagens. É certo que hoje já não faz sentido falar em censura externa aos meios de comunicação. $O$ que, porém, continua existindo é certa supervisão do Estado ou do empresariado sobre os procedimentos e métodos de trabalho destes mesmos meios.

A título de exemplo, recordamos as mudanças, às vésperas do pleito presiden- cial de 1994, das regras que normatizam as campanhas eleitorais através da TV, com a proibição do uso de cenas externas nos programas eleitorais dos partidos políticos. Pela nova regra, os partidos de oposição ficaram praticamente imobilizados, enquanto os partidos situacionistas ganhavam os espaços na programação normal e diária dos telejornais, alardeando os êxitos do Plano Econômico e da queda da inflação.

Ocorre, porém, que esse sistema de aliança vem passando, nos últimos tempos, por transformações, provocadas não necessariamente pela força da contestação de segmentos sociais que se julgam prejudicados, mas pela própria explosão tecnológica. São transformações que tanto ampliam o poder de intervenção dos denominados produtores culturais alternativos ou independentes, quanto abrem perspectivas de participação para os assim chamados "consumidores" ou "usuários" da indústria da informação da cultura, como, por exemplo, os educadores e seus alunos.

\section{O CRESCIMENTO SIGNIFICATIVO DA INCERTEZA}

Um dos fatores responsáveis pelo abalo da hegemonia das forças acima descritas tem sido a rapidez com que vem atuando, em nível mundial, uma série de novos atores sociais representados, por exemplo, pelos fabricantes de novos artefatos tecnológicos, principalmente no campo da informática e da telemática.

O caso dos satélites é exemplar: o espaço ocioso de seus equipamentos passou a permitir, por exemplo, a transmissão transnacional de programas de TV, fazendo com que esse tipo de difusão de informações fu-

2. GARNHAM, Nicholas, "La economía política de la comunicación, el caso de la televisión". Telos. Madrid, dez-fev. 1991, p.68-75. Veja-se, sobre o assunto, interessante matéria do jornal Folha de S.Paulo (edição de 15 de agosto de 1993): "Aqui agora vira salvador da pátria e deflagra violência", com o subtítulo: "Público vê repórteres do telejornal como substitutos informais do Estado". Diz a matéria: "Com seu estilo sensacionalista, o Aqui agora se transformou num campeão dos fracos e oprimidos. A frase 'vou chamar o Aqui agora' virou um bordão ameaçador que comerciantes, funcionários públicos e diretores de hospitais, entre outros, ouvem cada vez com maior freqüência". O programa de TV que chega a 30 pontos de audiência na Grande São Paulo já foi notícia no The New York Times. 
gisse, de certa forma, ao controle imediato dos governos nacionais.

Por sua vez, a difusão da TV a cabo vem sendo explosiva no mundo, segmentando de tal forma o mercado, que muitos analistas prevêem que em futuro próximo não haverá mais lugar para uma televisão comercial nos moldes daquela a que estamos acostumados ${ }^{3}$.

Mas, se por um lado as novas tecnologias reduzem a área de influência dos Governos, segmentam o mercado e multiplicam as opções tanto de produtos culturais quanto de usuários da comunicação, por outro, os antigos aliados estão longe de perder o que já conquistaram ao longo de várias décadas de interação com seus públicos: as grandes audiências.

Na verdade, os produtores tradicionais tiveram o tempo suficiente para criar padrões de produção/consumo de mensagens, construindo, com a cumplicidade de seus receptores, o que poderíamos denominar de "habitat comunicacional consensual", um espaço fluido no qual emoção, memória e imaginário se interpenetram em teias de representações domesticadas, permitindo a sensação da naturalidade do sistema e exigindo sua permanência.

Pode-se perceber, no entanto, um dado de natureza psicossocial: o crescimento significativo da incerteza, produzido justamente pelo mergulho das consciências nesse universo mágico, mas simultaneamente contraditório da produção cultural contemporânea.

A aparente perturbação da linearidade dos processos de comunicação representa, sem qualquer dúvida, um ganho de causa. A multiplicação dos signos em circuito, a fragilização das estratégias de controle cultural e a expansão do número dos atores sociais, beneficiam os grupos preocupados com a esponteneidade e autenticidade das expressões culturais.

\section{NOVAS ALIANÇAS}

Os novos atores, principalmente os que lutam para democratizar a esfera social em geral, manifestam-se cada vez mais preocupados com a conjutura comunicacional do mundo contemporâneo: "Como construir uma sociedade civil autônoma, quando a dimensão pública é cada vez mais controlada pelos media privados?" - pergunta-se Regina Festa, dando, como resposta: "Tudo isso significa repensar o conceito de serviço público atribuído pelo Estado aos mass media, em especial à televisão"4. Para a mesma autora, permitir que o aparato da comunicação funcione sem antes submetê-lo a uma democratização ampla é arriscar, na verdade minar, qualquer desenvolvimento democrático que esteja ocorrendo na esfera social.

Esse é o papel do exercício político da cidadania: garantir a vigência da democracia na sociedade e, para tanto, a vigência da democracia no sistema dos meios de comunicação. E existem muitos caminhos para exercer o dever cívico. Um deles é a vigilância em torno das leis que regulam o sistema de comunicação do país, outro, o da formação de novas alianças para a apropriação democrática dos recursos que a tecnologia vem colocando à disposição da população. Prerrogativa especial dos profissionais do ensino, o terceiro caminho é o da educação para a comunicação, aqui entendida em seu duplo sentido de capacitação para o uso dos recursos da comunicação e

3. Só nos EUA são 11.000 sistemas de TVs por cabo, enquanto, no Brasil, a rápida expansão do sistema e a recente aprovação de uma lei para a cabodifusão estão assinalando um futuro promissor para a área.

4. FESTA, Regina. Elementos para uma análise da comunicaşâo na América Latina: perspectivas para os anos 90 . Comunicação e Sociedade n (19), São Bernardo do Campo: IMS, 1993, p.75-76. 
de leitura crítica das mensagens dos meios massivos.

É neste contexto que defendemos, por exemplo, que o sistema de ensino formal se una a produtores culturais com maior experiência na área para incorporar as tecnologias da Comunicação Social no espaço educacional, permitindo aos professores e alunos lidar com os recursos da comunicação, convivendo com seus problemas e suas potencialidades.

Passos tímidos já têm sido dados. Lembro, a título de exemplo, a decisão de algumas instituições de ensino de São Pualo de acolher convite por nós formulado no sentido de realizar a experiência de produzir um programa de televisão para adolescentes.

O projeto patrocinado pelo Colégio São Luís, Província Marista e Inspetoria Salesiana de São Paulo permitiu, no primeiro semestre de 1995, a um grupo de animadores culturais e de alunos de mais de 20 colégios públicos e privados da captial paulista viver a experiência de planejar e elaborar com autonomia e liberdade de criação um produto cultural no qual definiram as pautas, decidiram o formato, acompanharam a finalização e promoveram a avaliação.

Os colégios, ao unirem seus educadores a profisssionais do vídeo, promoveram uma atividade de educação para a comunicação, permitindo a alguns de seus professores e alunos aprenderem como funciona a tecnologia da televisão e como é possível reconhecer, na prática, os vícios e as potencialidades do processo de produção cultural. Com o produto em mãos, os educadores se perguntam, agora, pelos espaços que devem "conquistar" para divulgar seu trabalho. Surge, para eles, a grande pergunta sobre a natureza política dos sistemas de comunicação.

Outro exemplo vem de Porto Alegre, onde o Projeto Vídeo-Criança, sob a orientação da produtora cultural Denise Cogo, vem permitindo a um grupo de adolescentes da periferia da cidade, em sua maioria de origem afro-brasileira, apropriar-se da linguagem da televisão para a produção de mensagens que documentam seu cotidiano de lutas e festas: aprendem a pensar e a sentir a partir de seu lugar social, econômico e político e aprendem a usar os meios de comunicação, como lhes é de direito.

Nos dois casos, as possibilidades do exercício da cidadania somente se tornam possíveis pela disposição dos agentes educacionais e culturais em superar as barreiras de seus próprios espaços institucionais e, principalmente, superar as barreiras do estritamente convencional, para a formação de novos tipos de alianças, sedimentadas num projeto político de fundo: o da democratização da comunicação.

\section{O PAPEL DO EDUCOMUNICADOR}

Cada dia mais, professores e estudantes dispõem-se a fazer uso das tecnologias da comunicação, isto é, a empregar algum recurso tecnológico (computador, vídeo, rádio, jornal) para transmitir suas mensagens.

A rápida difusão e o barateamento dos equipamentos têm possibilitado que mesmo instituições públicas ou estabelecimentos particulares de poucos recursos disponham de estruturas mínimas que acabam facilitando, quando há um pouco de criatividade, a realização dos projetos comunicacionais de seus corpos docentes e discentes.

O que efetivamente falta, no momento, é dar - à introdução das tecnologias da comunicação na escola - o sentido político exigido pelo delicado momento vivido pela humanidade, no limiar do século XXI. O que falta, para a maioria das escolas, é uma reflexão contextualizada sobre a realidade representada pela presença da comunicação na sociedade contemporânea. Uma reflexão que supere o inócuo deslumbramento frente às novas $\mathrm{e}$ sempre mutantes tecnologias. 
Uma reflexão incentivada e coordenada por um profissional capaz de, a partir das incertezas construídas pelo próprio sistema de meios massivos, construir caminhos seguros de expressão democrática no espaço da escola e da sociedade.

$\mathrm{O}$ profissional a que nos referimos denomina-se educomunicador, um agente cultural com conhecimentos suficientes no campo da educação e com manejo profundo das teorias, linguagens e técnicas da comunicação. Sobretudo, um profissional com capacidade de criação, para dar vida e sentido aos recursos colocados pela civilização a serviço de toda a humanidade. Trata-se de um verdadeiro gestor de processos comunicacionais 5 : faz nascer e gerencia projetos e produtos na área da comunicação nos espaço do ensino formal e não formal.

É ao educomunicador, que o escritor belga Armand Mattelart recorda que "o momento social em que vivemos está cheio de dispositivos que produzem controle e coação, que fabricam adesão e conformismo, mas é também feito de astúcias, inesgotáveis táticas, usos imprevisíveis dos recursos da informação, que preservam, na própria submissão, a liberdade do homem comum" 6 .

5. O Departamento de Comunicações e Artes (CCA) da ECA-USP oferece curso, em nível de Pós-graduação lato sensu, para a formação desse especialista. (N.E.)

6. MATTELART, Armand. Nuevos horizontes de la comunicación. Telos - Cuadernos de Comunicación, Tecnología y Sociedad. Madrid, n.37, março-abril de 1994, p.17-26. 